\title{
The phytochemical profiles for walnuts (J. regia and J. sigillata) from China with protected geographical indications
}

\author{
Ruohui WANG ${ }^{1 \&}$, Donglian ZHONG ${ }^{1 \&}$, Shutian WU1, Yongxiang $\mathrm{HAN}^{1}$, Yuewen ZHENG ${ }^{1}$, Fubin TANG ${ }^{1}$, \\ Zhanglin $\mathrm{NI}^{1 *}$, Yihua LIU ${ }^{1 *}$
}

\begin{abstract}
There is little research about walnuts with the certification of protected geographical indications (PGIs), especially about iron walnut. In this study, the comparison of phytochemical profiles for common walnut (Juglans. regia) and iron walnut (Juglans. sigillata) with PGIs was investigated. The results showed that common walnut has advantage in polyunsaturated fatty acids (71.43\%), polyphenols $(39.65 \mathrm{mg} / \mathrm{g})$, and flavonoids $(21.72 \mathrm{mg} / \mathrm{g})$, while iron walnut has advantage in $\alpha$-tocopherol and $\gamma$-tocopherol $(22.13 \mathrm{mg} / \mathrm{kg}$ and $420.72 \mathrm{mg} / \mathrm{kg}$ ) and nutritive elements $(\mathrm{Mn}, \mathrm{Ba}, \mathrm{Ni})$. Additionally, significant differences of palmitoleic acid, arachidic acid, eicosenoic acid, and flavonoids were existed in the two species walnuts, with highest variances of $87.05 \%$. Compared with walnuts in other reports, walnuts with protected geographical indications have a higher level of beneficial fatty acids, especially for monounsaturated fatty acid. Finally, highly positive correlations were observed among amino acids for all analyzed walnuts, and oleic acid was negatively correlated with linoleic acid.
\end{abstract}

Keywords: iron walnut; common walnut; phytochemical profiles; protected geographical indications; fatty acids.

Practical Application: The study shows the phytochemical profiles of geographical indication walnuts from China, these results will open promising perspectives for cultivation of walnut varieties and development of nutritional values.

\section{Introduction}

In all Juglans species, common walnuts (Juglans regia) are widely cultivated in more than 50 countries and regions. The phytochemical components and their nutritive effects in common walnuts had been investigated by many scientists. Common walnuts are rich in antioxidants and have notable effects in regulating blood lipid, cleaning thrombus, and immune regulation (Gao et al., 2018a). It is also considered to be a good source of minerals and essential amino acids (Zhai et al., 2014), which play vital roles in the living metabolism by involve the activity of enzymes and are associated with an improved health status (Trandafir et al., 2016). The common walnut oil contains numerous fatty acids, such as linoleic acid (C18:2), $\alpha$-linolenic acid (C18:3), and oleic acid (C18:1), whose contents are significantly higher than other nuts oils (such as pistachios, almonds, and macadamias) (Schlörmann et al., 2015). Among vegetable oils, walnut oil has one of the highest amounts of polyunsaturated fatty acids (PUFAs, up to $78 \%$ of the total fatty acids content), which can afford significant protective benefits in terms of both fatal and nonfatal coronary heart disease events (Simsek, 2016). Recently, many studies have dealt with the phytochemical compositions of walnuts from different countries, including Turkey (Simsek, 2016), Tunisia (Abdallah et al., 2015), Spain (Tapia et al., 2013), and Romania (Trandafir et al., 2016). The contents of fatty acids, mineral elements, proteins, antioxidant activity, amino acids, and aroma were documented.
China is the largest walnut producer worldwide, accounting for about $50 \%$ of the world's total production of walnut. However, little information is available on the chemical composition of walnuts harvested from China. Especially, few reports about the components of iron walnut (Juglans sigillata), the yield of which is more than $40 \%$ of the total Chinese walnut production (Gao et al., 2018b). Iron walnut (Juglans sigillata) is a special walnut variety in China. With regard to the systematic status of J. sigillata, there was a long-term, heated debate. It had been regarded as an ecotype of J. regia, but numerous botanists have viewed it as a different species. The most recent studies of ITS, RFLP, and cpDNA for J. regia and J. sigillata have concluded that they are a single species (Sun et al., 2019). Some scientists also found the differences among various phytochemical components in the two species of walnuts. The essential amino acids and some elements in kernels from 17 cultivars of common walnut and 11 cultivars of iron walnuts originated from China were determined, in which the orders of these compositions were different (Zhai et al., 2014). The fatty acids composition of six walnut oil samples (3 common walnuts, 3 iron walnuts) collected from Yunnan Province of China were also compared, in which C16:1, C22:0, and C22:1 only found in iron walnut (Gao et al., 2019). Obviously, the limited studies could not comprehensively reveal whether the two species are distinct in their compositions. 
In this work, we collected samples with the certification of protected geographical indications (PGIs) to investigate the comprehensive compositions of the two species. As we all know, the foods with the PGIs have special qualities and reputation, which may help the foods earn good economic effects in the market. The results of this work are not only helpful to understand the quality of Chinese walnuts, but also give more information to know the two species of walnuts from the view of chemistry.

\section{Materials and methods}

\subsection{Reagents and standards}

HPLC grade hexane (methanol, isooctane, isopropanol, and analytical grade nitric acid) were obtained from Thermo Fisher (Thermo Fisher Scientific, America). All analytical grade reagents were purchased from Wako Pure Chemical Industries, Ltd (Japan) or Beijing Chemical Reagent Company (Beijing, China). Folin-Ciocalteu reagent (Sigma-Aldrich) was used for colorimetric analysis. The following certified standards were used: 37 component FAME Mix in dichloromethane (Sigma-Aldrich, USA); Amino acid standard solution (Sigma-Aldrich, USA); tocopherols $(\alpha-, \beta-, \gamma$-, and $\delta$ ) (purity $\geq 95 \%$ by HPLC) were obtained from Supelco (Sigma-Aldrich, USA); rutin and gallic acid (purity $\geq 98 \%$ by HPLC) were purchased by National Institutes for Food and Drug Control (Beijing, China). Multi element standard solutions containing $100 \mathrm{mg} \mathrm{L}^{-1}$ of each element were supplied by the National Analysis Center of Iron and Steel (NCS, Beijing, China). A certified reference material (Green bean powder, GBW10021, National Research Center for Certified Reference Materials, Beijing, China) was used to verify the accuracy of the results.

\subsection{Sample collection}

The walnut samples were collected from the typical producing regions of China where produce the walnuts with the certification of protected geographical indications (Iron walnut: Xizang region; Guizhou region; Yunnan region. Common walnut: Shaanxi region; Shanxi region; Xinjiang region; Hebei region; Gansu region; Sichuan region). All samples came from the local orchard at each region in 2017 during mature stage. All walnut kernels and oil were prepared and kept frozen $\left(-20^{\circ} \mathrm{C}\right)$ until analysis.

\subsection{Fatty acid composition}

Before esterification, walnut oil was extracted by Soxhlet extraction method. Then the oil samples were esterificated according to ISO-5509 method. Fatty acid methyl esters of oils were analyzed using 7890A gas chromatography (Agilent Technologies, USA) equipped with a flame ionization detector (GC-FID) and capillary column (HP-INNOWAX, $30 \mathrm{~m} \times 0.32 \mathrm{~mm} \times 0.25 \mu \mathrm{m}$ ).

\subsection{Tocopherols contents}

The extraction and the analysis of the tocopherols were performed on the walnut samples as described by Han et al. (2019).

\subsection{Total flavonoids and total polyphenols content}

The extraction and the analysis of the total flavonoids and total polyphenols were performed on the walnut samples as described by Han et al. (2019).

\subsection{Amino acids}

Amino acids of walnut samples were determined by L- 8900 automatic amino acid analyze (Hitachi High Technologies Corporation, Tokyo, Japan). Approximately $0.1 \mathrm{~g}$ sample was weighed into $35 \mathrm{~mL}$ hydrolysid tube, then was hydrolyzed with $10 \mathrm{~mL}$ hydrochloric acid $(6 \mathrm{M})$ at $105^{\circ} \mathrm{C}$ for $24 \mathrm{~h}$ under nitrogen atmosphere.

\subsection{Mineral composition}

The mineral compositions of walnut sample were determined according to the method developed in our previous research (Han et al., 2018). Walnut sample was digested with $6 \mathrm{~mL}$ nitric acid $\left(\mathrm{HNO}_{3}, 65 \%\right)$ and $2 \mathrm{~mL}$ hydrogen peroxide $\left(\mathrm{H}_{2} \mathrm{O}_{2}, 30 \%\right)$ using microwave oven (CEM, Matthews, NC, USA). Then the solution was for ICP-OES (K, Ca, P, Cu, Zn, Fe, Mn) and ICP-MS (Ba) analysis.

\subsection{Statistical analysis}

The results were shown as mean \pm standard deviation. The statistical differences of the measured data were calculated by analysis of variance (ANOVA). The statistical significance $(p<0.05)$ between different species was analyzed using by $t$-test using SPSS, version 19.0 (IBM, USA). The correspondence analysis between different phytochemical components of walnuts was analyzed by $\mathrm{R}$ language with R 3.5.2.

\section{Results and discussion}

\subsection{The profiles of fatty acids in the two kinds of walnuts}

The fatty acid compositions of iron walnut and common walnut are shown in Table 1. The main identified compositions were linoleic acid (C18:2), oleic acid (C18:1), linolenic acid (C18:3), palmitic acid (C16:0), and stearic acid (C18:0). The results also found some minor fatty acids in the two kinds of walnuts, such as palmitoleic acid (C16:1), arachidic acid (C20:0), and eicosenoic acid (C20:1). The percentage of C16:1 for common walnut is in agreement with those reported in Spain (Bada et al., 2010). However, common walnuts from Serbia could not be found C16:1 (Rabrenovic et al., 2008).

Among fatty acids, PUFA is considered as an important and special composition for walnut, the level of which was even found to be the highest among various nuts (Kim et al., 2013). Interestingly, the content of PUFA in common walnut was higher than that in iron walnut, which could be found in this study and other previous report (Gao et al., 2019). Among PUFA, the percentages of $\mathrm{C} 18: 2$ were adjacent to $60 \%$ in the two kinds of walnuts, which were higher than the results found in walnuts of Turkey (Yerlikaya et al., 2012) and Spain (Tapia et al., 2013). The performance might be due to our samples collected from 
Table 1. Fatty acids composition (\%) of iron walnut and common walnut.

\begin{tabular}{|c|c|c|c|c|c|c|c|}
\hline & \multicolumn{3}{|c|}{ iron walnut } & \multicolumn{3}{|c|}{ common walnut } & \multirow{2}{*}{$P$} \\
\hline & range $(\%)$ & average (\%) & std & range $(\%)$ & average (\%) & std & \\
\hline $\mathrm{C} 16: 0$ & $5.09-8.73$ & 6.63 & 0.13 & $4.67-7.33$ & 5.94 & 0.08 & 0.00 \\
\hline $\mathrm{C} 16: 1$ & $0.00-0.22$ & 0.07 & 0.01 & $0.00-0.02$ & 0.04 & 0.01 & 0.03 \\
\hline C18:0 & $1.16-3.36$ & 2.27 & 0.07 & $1.92-3.81$ & 2.70 & 0.06 & 0.00 \\
\hline C18:1 & $12.05-38.68$ & 22.08 & 0.87 & $13.74-36.30$ & 19.89 & 0.52 & 0.02 \\
\hline $\mathrm{C} 18: 2$ & $42.72-73.06$ & 59.45 & 0.94 & $47.82-67.48$ & 61.30 & 0.45 & 0.04 \\
\hline C18:3 & $6.35-25.92$ & 9.20 & 0.50 & $6.34-13.48$ & 9.80 & 0.18 & 0.19 \\
\hline C20:0 & $0.00-0.08$ & 0.01 & 0.00 & $0.00-0.10$ & 0.02 & 0.01 & 0.09 \\
\hline C20:1 & $0.00-0.21$ & 0.09 & 0.01 & $0.00-0.21$ & 0.14 & 0.01 & 0.00 \\
\hline SFA & $7.13-11.27$ & 8.91 & 0.12 & $7.47-9.56$ & 8.67 & 0.06 & 0.06 \\
\hline MUFA & $12.21-38.89$ & 22.25 & 0.88 & $13.92-36.55$ & 20.07 & 0.53 & 0.03 \\
\hline PUFA & $53.98-79.66$ & 68.65 & 0.81 & $55.27-77.43$ & 71.11 & 0.51 & 0.01 \\
\hline
\end{tabular}

Note: std: standard deviation, SFA: saturated fatty acid, MUFA: monounsaturated fatty acid, PUFA: polyunsaturated fatty acids, $P: P$ value.

the regions with the certification of PGIs. The advantages of the samples from PGIs were also found in the contents of MUFA. Our result of MUFA content in common walnut was 20.07\%, which was obviously higher than those from from Tunisia (15.72\%) (Bouabdallah et al., 2014), Italy (16.49\%) (Poggetti et al., 2018) and even other regions of China (17.56\%) (Liu et al., 2020). The average content of MUFA in iron walnut from our results (22.25\%) was also higher than that corresponding sample from Xinjiang Uygur Autonomous region (18.42\%) (Gao et al., 2018b). Popescu et al. (2015) considered that the differences in fatty acids composition could be partly due to geographical origin. We agreed this opinion and further thought the walnut species also was an important factor for the explanation of the differences in fatty acids composition. At the same time, walnuts with the certification of PGIs have a higher level of beneficial fatty acids.

\subsection{The contents of antioxidants in the two kinds of walnuts}

The findings for walnuts antioxidant contents were polyphenols, flavonoids, and tocopherols (Ve), as is reflected in Figure 1. Obviously, except for Ve, the detected antioxidant contents in common walnut were higher than those in iron walnut (Figure 1A). The result was also found in previous study (Gao et al., 2019). Meanwhile, the content of polyphenols from this work was ranged from 12.95 to $61.45 \mathrm{mg} / \mathrm{g}$ in common walnut. Gao et al. (2019) found the polyphenols content in common walnut was 2-3 times higher than that in iron walnut. However, it only observed less than 2 times higher than iron walnut. The different performance might be due to the cultivar, stage of maturity, year of harvest, storage conditions or extraction procedure, which were the factors related to polyphenols biosynthesis (Cerit et al., 2017). In addition, the polyphenols and flavonoids contents in common walnut were higher than those in iron walnut. However, the opposite result was observed in Ve, in which the Ve contents were $510.42 \mathrm{mg} / \mathrm{kg}$ (iron walnut) and $418.87 \mathrm{mg} / \mathrm{kg}$ (common walnut), respectively. Moreover, the four homologues of $\mathrm{Ve}\left(\alpha-, \beta-, \gamma^{-}\right.$, and $\delta$-) were also various between the two kinds of walnuts (Figure 1B). Notably, $\beta$-Ve had the

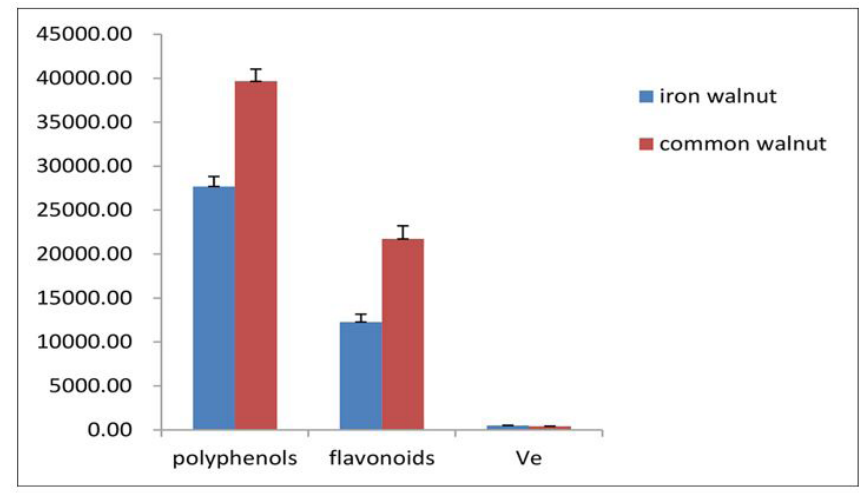

(A)

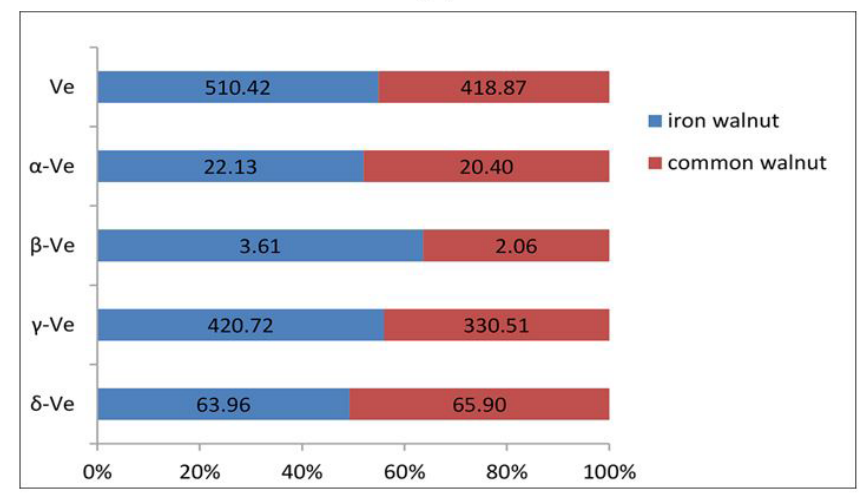

(B)

Figure 1. The concentrations of antioxidants (A) and the compositions of $\mathrm{Ve}(\mathrm{B})$ in the two kinds of walnuts.

highest difference between iron walnut and common walnut, the ratio of the mean content in iron walnut to common walnut was 1.75 . The $\delta$-Ve values of iron walnut $(30.24-103.13 \mathrm{mg} / \mathrm{kg}$ ) were in accordance with the common walnut in this study $(32.61-87.47 \mathrm{mg} / \mathrm{kg})$, but the results were higher than iron walnut reported in other regions of China $(36.88-45.19 \mathrm{mg} / \mathrm{kg})$ (Gao et al., 2018b). Therefore, the observed difference may be 
due to the location conditions, genetic effects or extraction techniques as reported by previous study (Gao et al., 2019). Interestingly, researchers (Li et al., 2007; Zhai et al., 2015) have proved that $\beta$-Ve was not detected in common walnut of their studies. Specially, Zhai et al. (2015) even found no $\alpha$-Ve in common walnut. The above performance showed that walnut species may affect the Ve contents.

\subsection{The contents of amino acid in the two kinds of walnuts}

Amino acid composition is an important chemical property of proteins, as it determines their nutritional value. According to Table 2, 17 amino acids including ten kinds of non-essential amino acids (NEAA) and seven essential amino acids (EAA) were detected from the kernels of iron walnut and common walnut. The two species contained appreciable amounts of total amino acids, with $160.27 \mathrm{mg} / \mathrm{g}$ in iron walnut and $153.64 \mathrm{mg} / \mathrm{g}$ in common walnut, respectively.

Glutamic acid (Glu), arginine (Arg), and aspartic acid (Asp) were the most abundant in all the samples, accounting for nearly $50 \%$ of the total amino acids. The similar results were also observed in common walnuts from a region of China (Liu et al., 2020) and other nuts from Korea (Chung et al., 2013). Notably, the relatively low content of Lys and high levels of Arg were in consistent with Ruggeri et al. (1999). It even can be identified as a positive feature for walnuts. The mean ratio of Lys/Arg for the two kinds of walnut was 0.19, which was lower than other samples (0.24) (Savage, 2001). Arg is the precursor of the endogenous vasodilator. Additionally, it is necessary for EAA to evaluate the protein quality. They also play a key role in the development of body since they are not synthesized by people

Table 2. Amino acids contents $(\mathrm{mg} / \mathrm{g})$ of the two kinds of walnuts.

\begin{tabular}{|c|c|c|c|c|}
\hline & & iron walnut & $\begin{array}{c}\text { common } \\
\text { walnut }\end{array}$ & average \\
\hline \multirow{9}{*}{ 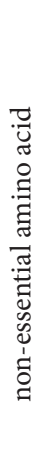 } & Glu & $33.86 \pm 0.59$ & $31.77 \pm 0.56$ & $32.61 \pm 0.42$ \\
\hline & Arg & $24.35 \pm 0.46$ & $23.76 \pm 0.38$ & $24.00 \pm 0.29$ \\
\hline & Asp & $16.16 \pm 0.27$ & $15.60 \pm 0.23$ & $15.83 \pm 0.18$ \\
\hline & Ser & $8.87 \pm 0.14$ & $8.39 \pm 0.11$ & $8.58 \pm 0.09$ \\
\hline & Gly & $8.20 \pm 0.14$ & $7.61 \pm 0.10$ & $7.85 \pm 0.08$ \\
\hline & Ala & $7.18 \pm 0.12$ & $6.82 \pm 0.09$ & $6.96 \pm 0.07$ \\
\hline & Tyr & $5.55 \pm 0.10$ & $5.34 \pm 0.07$ & $5.42 \pm 0.06$ \\
\hline & Pro & $5.50 \pm 0.09$ & $4.86 \pm 0.20$ & $5.12 \pm 0.13$ \\
\hline & Cys & $3.97 \pm 0.10$ & $3.93 \pm 0.09$ & $3.95 \pm 0.06$ \\
\hline \multirow{8}{*}{ 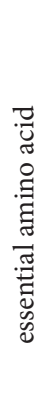 } & His & $3.95 \pm 0.07$ & $3.82 \pm 0.05$ & $3.88 \pm 0.04$ \\
\hline & Leu & $11.72 \pm 0.23$ & $11.21 \pm 0.17$ & $11.41 \pm 0.14$ \\
\hline & Phe & $7.05 \pm 0.12$ & $7.01 \pm 0.10$ & $7.03 \pm 0.08$ \\
\hline & Val & $6.55 \pm 0.15$ & $6.41 \pm 0.09$ & $6.47 \pm 0.08$ \\
\hline & Ile & $5.89 \pm 0.13$ & $5.70 \pm 0.08$ & $5.77 \pm 0.07$ \\
\hline & Thr & $5.34 \pm 0.08$ & $5.37 \pm 0.07$ & $5.36 \pm 0.06$ \\
\hline & Lys & $4.57 \pm 0.09$ & $4.50 \pm 0.06$ & $4.53 \pm 0.05$ \\
\hline & Met & $1.57 \pm 0.03$ & $1.55 \pm 0.04$ & $1.56 \pm 0.03$ \\
\hline
\end{tabular}

(Zhai et al., 2014). As can be seen in the Table 2, the contents of leucin acid (Leu) was higher than other EAA, with the values ranged from 8.74 to $15.15 \mathrm{mg} / \mathrm{g}$ in iron walnut, and 8.42 to $14.63 \mathrm{mg} / \mathrm{g}$ in common walnut, respectively. Besides, the value of total EAA was 1.36 times higher than that of total NEAA in common walnut, which was similar with iron walnut.

Generally, whether the specific amino acid or the total ones. The differences of the amino acids contents in iron walnut and common walnut were insignificant $(p>0.05)$. It may demonstrate that the compositions of amino acids did not relate to the species.

\subsection{The contents of mineral elements in the two kinds of walnuts}

As we all know, the kernels of walnut have a remarkable amount of mineral nutrition that is beneficial to body health among common foodstuffs. In common walnut, the contents of $\mathrm{Mg}, \mathrm{Fe}$, and $\mathrm{Cu}$ were notable high than those from non PGI regions (Ozcan, 2009), even up to $50 \%$. The results showed our samples with the certification of PGIs had an advantage in some nutritive elements. The similar performances were also found in Malatya apricot (Akin et al., 2008) and Vatikiotiko onion (Petropoulos et al., 2015), in which the geographical indication products contained high nutritional values. Furthermore, previous study even provided mineral compositions could be a useful parameter to discriminate the production from different GI (Gambetta et al., 2017).

In addition, compared with common walnut, the contents of $\mathrm{Ba}, \mathrm{Ni}$, and $\mathrm{Mn}$ were particularly higher in iron walnut (Figure 2). The Ba content in iron walnut was even up to 3 times higher than that in common walnut. Zhai et al. (2014) found the most significant difference between the two species existed in $\mathrm{Mn}$, the ratio of the mean contents of $\mathrm{Mn}$ in iron walnut to common walnut was 1.76. Meanwhile, the ratio of $\mathrm{Mn}$ in this study was 1.67. However, some elements composition, such as $\mathrm{Ca}, \mathrm{Fe}, \mathrm{Zn}$, and $\mathrm{Cu}$, of common walnut were higher than those in iron walnut. As a result of this study, the differences in mineral composition between the two kinds of walnut could be due to the effect of genotype and environmental factors.

\subsection{The components correlations between iron walnut and common walnut}

In addition to analyzing the phytochemical profiles of the two kinds of walnut, we also investigated the inherent relationships of them. As shown in Figure 3, significant positive correlations were found for many kinds of phytochemical components. Especially, highly positive correlations were observed among nearly all amino acids $(r>0.53, p<0.05)$. The high correlation is the embodiment of intricate mechanisms in the synthesis and metabolic processes of amino acids (Martinez-Jarquin et al., 2017). Nevertheless, surprisingly, amino acids were only correlated with partial mineral elements $(\mathrm{B}, \mathrm{V}$, and $\mathrm{Ti})$ in the two kinds of walnuts. Though, mineral elements are an essential part of many important enzymes and they play roles as catalysts and antioxidants (Gharibzahedi et al., 2014). Besides, more positive associations among mineral elements were found in common walnut. It may suggested that the close relation between them. 


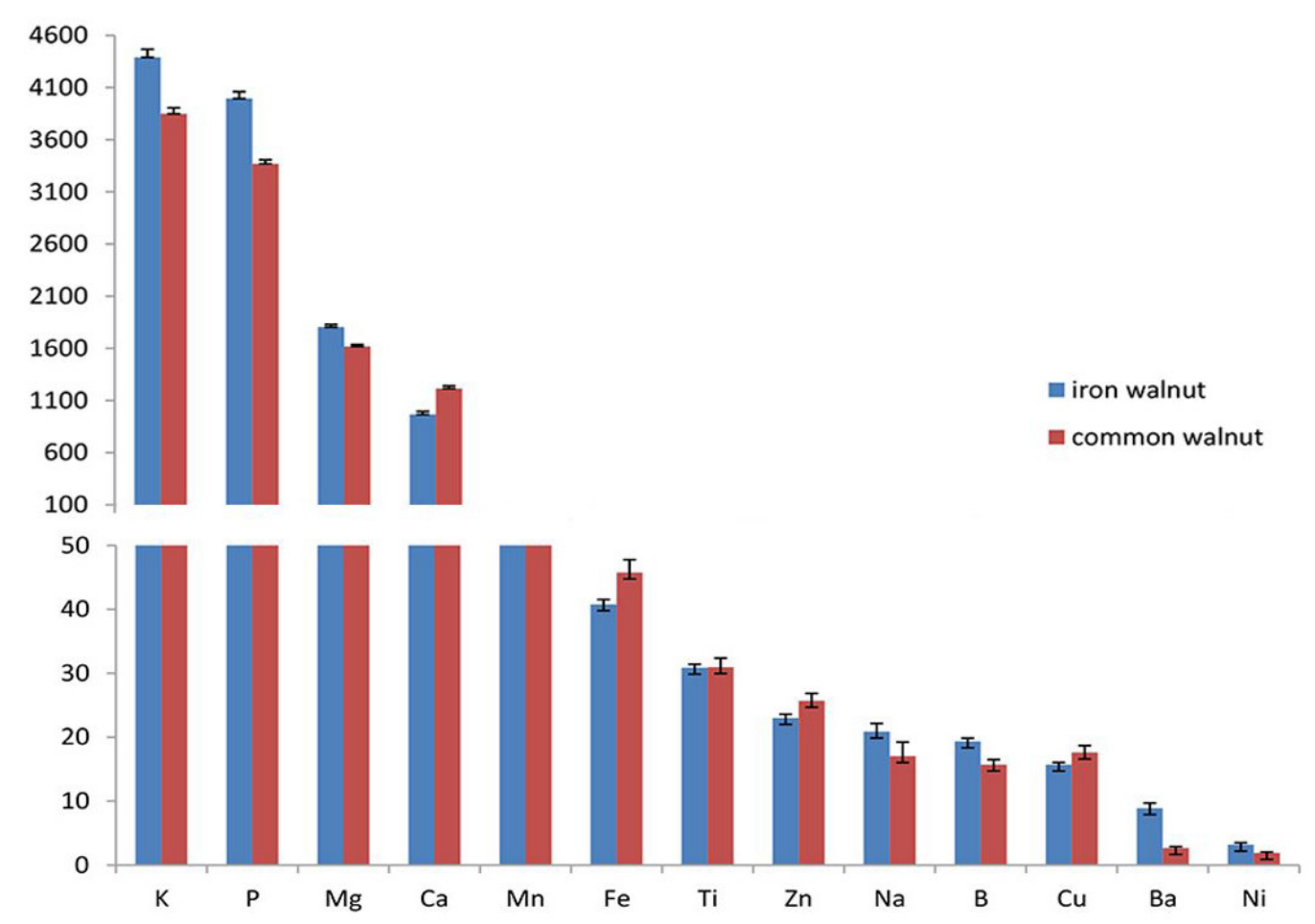

Figure 2. The average contents of mineral elements in iron walnut and common walnut.

Except for positive correlations, there were some negative correlations among phytochemical components. It concluded that $\mathrm{C} 18: 1$ was negatively correlated with $\mathrm{C} 18: 2$ in iron walnut and common walnut, which concurred with the relationship in common walnut reported by Gao et al. (2019) and in iron walnut reported by Shi et al. (2018). The phenomenon can explained by that $\mathrm{C} 18: 2$ will accumulates when the fruit matures, and the substrate of $\mathrm{C} 18: 2$ is $\mathrm{C} 18: 1$, the residual amount of $\mathrm{C} 18: 1$ is reduced (Shi et al., 2018). Besides, a previous study (Li et al., 2017) found a significantly negative correlation between $\mathrm{C} 18: 1$ and $\mathrm{C} 18: 3$ $(r=0.50, p<0.05)$ in common walnut, while the similar result were not found in the present study. The results demonstrated that the negative correlation between the unsaturated fatty acids might be not related to the species of walnuts. Interestingly, although there were no significant correlations between C20:1 and other components in iron walnut, some negative correlations among C20:1, elements and amino acids in common walnut were found. The reason should be further explored.

\section{Conclusion}

Comprehensive information concerning the variances and correlations of phytochemical components in iron walnut and common walnut from PGI regions were analyzed. The differences of most components existed in the two species walnuts, especially for some fatty acids and total flavonoids. The values of PUFA, polyphenols and flavonoids were rich in common walnut, while iron walnut provided higher tocopherols and some nutritive elements. Based on correlation analysis, highly positive correlations of most amino acids and negative correlations of minor fatty acids (C18:1 and C18:2) were observed in all analyzed walnuts. These data will open promising perspectives

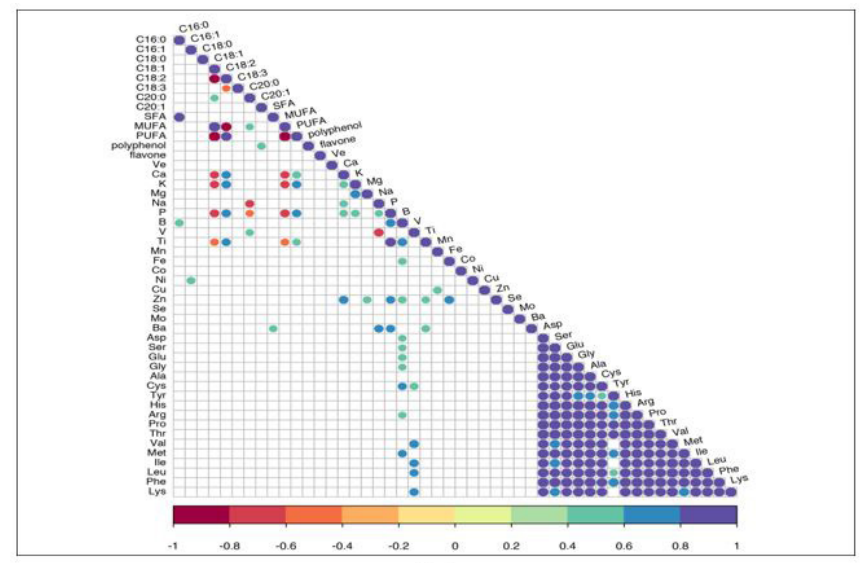

(A)

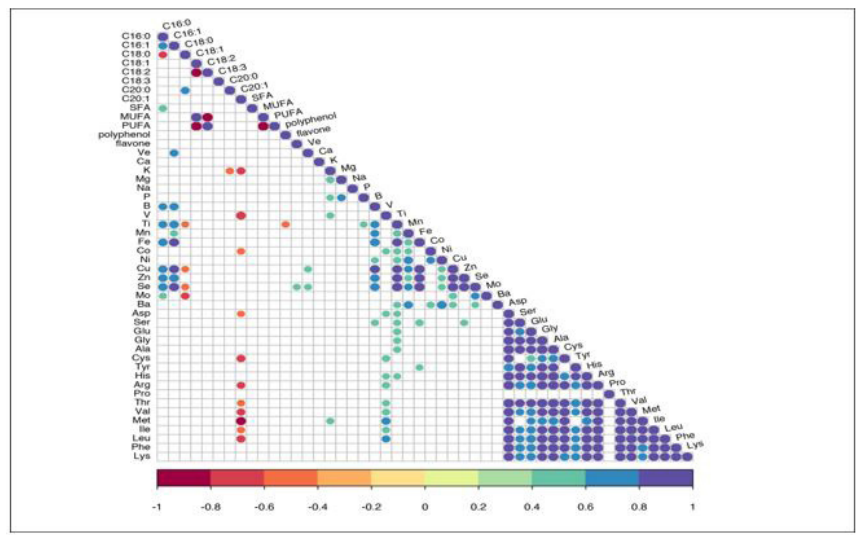

(B)

Figure 3. The correlations of phytochemical components in walnut. (A) iron walnut; (B) common walnut. 
for cultivation of walnut varieties and development of nutritional values. Additionally, we found that walnuts with protected geographical indications have a higher level of beneficial fatty acids. The indicators are important to the consumption and uses of walnut oil from PGI regions.

\section{Acknowledgements}

This study was supported by the Fundamental Research Funds of CAF (CAFYBB2017QC002 and CAFYBB2019QD002).

\section{References}

Abdallah, I. B., Tlili, N., Martinez-Force, E., Rubio, A. G., Perez-Camino, M. C., Albouchi, A., \& Boukhchina, S. (2015). Content of carotenoids, tocopherols, sterols, triterpenic and aliphatic alcohols, and volatile compounds in six walnuts (Juglans regia L.) varieties. Food Chemistry, 173, 972-978. http://dx.doi.org/10.1016/j.foodchem.2014.10.095. PMid:25466114.

Akin, E. B., Karabulut, I., \& Topcu, A. (2008). Some compositional properties of main Malatya apricot (Prunus armeniaca L.) varieties. Food Chemistry, 107(2), 939-948. http://dx.doi.org/10.1016/j. foodchem.2007.08.052.

Bada, J. C., Leon-Camacho, M., Prieto, M., Copovi, P., \& Alonso, L. (2010). Characterization of walnut oils (Juglans regia L.) from Asturias, Spain. Journal of the American Oil Chemists' Society, 87(12), 1469-1474. http://dx.doi.org/10.1007/s11746-010-1629-3.

Bouabdallah, I., Bouali, I., Martinez-Force, E., Albouchi, A., Perez Camino, M. C., \& Boukhchina, S. (2014). Composition of fatty acids, triacylglycerols and polar compounds of different walnut varieties (Juglans regia L.) from Tunisia. Natural Product Research, 28(21), 1826-1833. http://dx.doi.org/10.1080/14786419.2014.950 573. PMid:25142132.

Cerit, I., Saricam, A., Demirkol, O., Unver, H., Sakar, E., \& Cosansu, S. (2017). Comparative study of functional properties of eight walnut (Juglans regia L.) genotypes. Food Science and Technology, 37(3), 472-477. http://dx.doi.org/10.1590/1678-457x.20516.

Chung, K. H., Shin, K. O., Hwang, H. J., \& Choi, K. S. (2013). Chemical composition of nuts and seeds sold in Korea. Nutrition Research and Practice, 7(2), 82-88. http://dx.doi.org/10.4162/nrp.2013.7.2.82. PMid:23610599.

Gambetta, J. M., Cozzolino, D., Bastian, S. E. P., \& Jeffery, D. W. (2017). Exploring the effects of geographical origin on the chemical composition and quality grading of Vitis vinifera L. cv. Chardonnay Grapes. Molecules, 22(2), 218. http://dx.doi.org/10.3390/molecules22020218. PMid:28146133.

Gao, P., Jin, J., Liu, R. J., Jin, Q. Z., \& Wang, X. G. (2018a). Chemical compositions of walnut (Juglans regia $\mathrm{L}$.) oils from different cultivated regions in China. Journal of the American Oil Chemists' Society, 95(7), 825-834. http://dx.doi.org/10.1002/aocs.12097.

Gao, P., Liu, R. J., Jin, Q. Z., \& Wang, X. G. (2018b). Comparison of different processing methods of iron walnut oils (Juglans sigillata): lipid yield, lipid compositions, minor components, and antioxidant capacity. European Journal of Lipid Science and Technology, 120(9), 9. http://dx.doi.org/10.1002/ejlt.201800151.

Gao, P., Liu, R. J., Jin, Q. Z., \& Wang, X. G. (2019). Comparative study of chemical compositions and antioxidant capacities of oils obtained from two species of walnut: Juglans regia and Juglans sigillata. Food Chemistry, 279, 279-287. http://dx.doi.org/10.1016/j. foodchem.2018.12.016. PMid:30611491.
Gharibzahedi, S. M. T., Mousavi, S. M., Hamedi, M., \& Khodaiyan, F. (2014). Determination and characterization of kernel biochemical composition and functional compounds of Persian walnut oil. Journal of Food Science and Technology-Mysore, 51(1), 34-42. http://dx.doi. org/10.1007/s13197-011-0481-2. PMid:24426045.

Han, Y. X., Ni, Z. L., Li, S. L., Qu, M. H., Tang, F. B., Mo, R. H., Ye, C., \& Liu, Y. (2018). Distribution, relationship, and risk assessment of toxic heavy metals in walnuts and growth soil. Environmental Science and Pollution Research International, 25(18), 17434-17443. http:// dx.doi.org/10.1007/s11356-018-1896-3. PMid:29656354.

Han, Y. X., Zheng, Y. W., Li, S. L., Mo, R. H., Long, X. Y., \& Liu, Y. H. (2019). Effects of drying process with different temperature on the nutritional qualities of walnut (Juglans regia L.). Food Science and Technology Research, 25(2), 167-177. http://dx.doi.org/10.3136/ fstr.25.167.

Kim, J. K., Shin, E. C., Kim, C. R., Park, G. G., Choi, S. J., Cho, H. Y., \& Shin, D. H. (2013). Composition of fatty acids in commercially available tree nuts and their relationship with protective effects against oxidative stress-induced neurotoxicity. Food Science and Biotechnology, 22(4), 1097-1104. http://dx.doi.org/10.1007/s10068013-0189-3.

Li, L., Tsao, R., Yang, R., Kramer, J. K. G., \& Hernandez, M. (2007). Fatty acid profiles, tocopherol contents, and antioxidant activities of heartnut (Juglans ailanthifolia Var. cordiformis) and persian walnut (Juglans regia L.). Journal of Agricultural and Food Chemistry, 55(4), 1164-1169. http://dx.doi.org/10.1021/jf062322d. PMid:17253708.

Li, Q., Yin, R., Zhang, Q. R., Wang, X. P., Hu, X. J., Gao, Z. D., \& Duan, Z. M. (2017). Chemometrics analysis on the content of fatty acid compositions in different walnut (Juglans regia L.) varieties. European Food Research and Technology, 243(12), 2235-2242. http://dx.doi. org/10.1007/s00217-017-2925-z.

Liu, B. H., Liang, J., Zhao, D. C., Wang, K. F., Jia, M., \& Wang, J. (2020). Morphological and compositional analysis of two walnut (Juglans regia L.) cultivars growing in China. Plant Foods for Human Nutrition, 75(1), 116-123. http://dx.doi.org/10.1007/s11130-019-00794-y. PMid:31925636.

Martinez-Jarquin, S., Moreno-Pedraza, A., Cazarez-Garcia, D., \& Winkler, R. (2017). Automated chemical fingerprinting of Mexican spirits derived from Agave (tequila and mezcal) using direct-injection electrospray ionisation (DIESI) and low-temperature plasma (LTP) mass spectrometry. Analytical Methods, 9(34), 5023-5028. http:// dx.doi.org/10.1039/C7AY00793K.

Ozcan, M. M. (2009). Some nutritional characteristics of fruit and oil of walnut (Juglans regia L.) growing in Turkey. Iranian Journal of Chemistry \& Chemical Engineering-International English Edition, 28(1), 57-62.

Petropoulos, S. A., Fernandes, A., Barros, L., Ferreira, I. C. F. R., \& Ntatsi, G. (2015). Morphological, nutritional and chemical description of "Vatikiotiko", an onion local landrace from Greece. Food Chemistry, 182, 156-163. http://dx.doi.org/10.1016/j.foodchem.2015.03.002. PMid:25842322.

Poggetti, L., Ferfuia, C., Chiaba, C., Testolin, R., \& Baldini, M. (2018). Kernel oil content and oil composition in walnut (Juglans regia L.) accessions from north-eastern Italy. Journal of the Science of Food and Agriculture, 98(3), 955-962. http://dx.doi.org/10.1002/jsfa.8542. PMid:28703854.

Popescu, R., Costinel, D., Dinca, O. R., Marinescu, A., Stefanescu, I., \& Ionete, R. E. (2015). Discrimination of vegetable oils using NMR spectroscopy and chemometrics. Food Control, 48, 84-90. http:// dx.doi.org/10.1016/j.foodcont.2014.04.046. 
Rabrenovic, B., Picuric-Jovanovic, K., \& Sobajic, S. (2008). Physicochemical properties and fatty acid composition of Juglans regia cultivars grown in Serbia. Chemistry of Natural Compounds, 44(2), 151-154. http:// dx.doi.org/10.1007/s10600-008-9000-8.

Ruggeri, S., Cappelloni, M., Gambelli, L., Nicoli, S., \& Carnovale, E. (1999). Chemical composition and nutritive value of nuts grown in Italy. Italian Food \& Beverage Technology, (15), 12-17.

Savage, G. P. (2001). Chemical composition of walnuts (Juglans regia L.) grown in New Zealand. Plant Foods for Human Nutrition, 56(1), 75-82. http://dx.doi.org/10.1023/A:1008175606698. PMid:11213171.

Schlörmann, W., Birringer, M., Bohm, V., Lober, K., Jahreis, G., Lorkowski, S., Müller, A. K., Schöne, F., \& Glei, M. (2015). Influence of roasting conditions on health-related compounds in different nuts. Food Chemistry, 180, 7785. http://dx.doi.org/10.1016/j.foodchem.2015.02.017. PMid:25766804.

Shi, B. B., Zhang, W. N., Li, X., \& Pan, X. J. (2018). Seasonal variations of phenolic profiles and antioxidant activity of walnut (Juglans sigillata Dode) green husks. International Journal of Food Properties, 20(Suppl. 3), S2635-S2646. http://dx.doi.org/10.1080/10942912.2017.1381706.

Simsek, M. (2016). Chemical, mineral, and fatty acid compositions of various types of walnut (Juglans regia L.) in Turkey. Izvestiia po Himiia, 48(1), 66-70.

Sun, Y. W., Hou, N., Woeste, K., Zhang, C., Yue, M., Yuan, X. Y., \& Zhao, P. (2019). Population genetic structure and adaptive differentiation of iron walnut Juglans regia subsp. sigillata in southwestern China. Ecology and Evolution, 9(24), 14154-14166. http://dx.doi.org/10.1002/ ece3.5850. PMid:31938510.
Tapia, M. I., Sánchez-Morgado, J. R., García-Parra, J., Ramírez, R., Hernández, T., \& González-Gómez, D. (2013). Comparative study of the nutritional and bioactive compounds content of four walnut (Juglans regia L.) cultivars. Journal of Food Composition and Analysis, 31(2), 232-237. http://dx.doi.org/10.1016/j. jfca.2013.06.004.

Trandafir, I., Cosmulescu, S., Botu, M., \& Nour, V. (2016). Antioxidant activity, and phenolic and mineral contents of the walnut kernel (Juglans regia L.) as a function of the pellicle color. Fruits, 71(3), 177-184. http://dx.doi.org/10.1051/fruits/2016006.

Yerlikaya, C., Yucel, S., Erturk, U., \& Korukluoglu, M. (2012). Proximate composition, minerals and fatty acid composition of Juglans regia L. genotypes and cultivars grown in Turkey. Brazilian Archives of Biology and Technology, 55(5), 677-683. http://dx.doi.org/10.1590/ S1516-89132012000500006.

Zhai, M. Z., Wang, D., Tao, X. D., \& Wang, Z. Y. (2015). Fatty acid compositions and tocopherol concentrations in the oils of 11 varieties of walnut (Juglans regia L.) grown at Xinjiang, China. The Journal of Horticultural Science \& Biotechnology, 90(6), 715-718. http://dx.doi. org/10.1080/14620316.2015.11668736.

Zhai, M., Wang, Z., Wang, D., Xu, J., \& Shi, G. (2014). Comparative analysis of mineral elements and essential amino acids compositions in Juglans sigillata and J. regia walnuts kernels. Notulae Botanicae Horti Agrobotanici Cluj-Napoca, 42(1), 36-42. http://dx.doi.org/10.15835/ nbha4219426. 